\title{
System Reliability Optimization with Fuzzy Goals Using Genetic Algorithm ${ }^{\dagger}$
}

\author{
Mitsuo GEN* Kenichi IDA* Jongryul KIM*
}

\section{Introduction}

Integer programming(IP) is a mathematical model designed to find a set of non-negative integer variables to optimize a function while satisfying a system of constraints. An IP model having integer variables and other variables like a real variable is called a mixed integer programming (MIP). Generally, to solve the MIP problem, the branch and bound $(B \& B)$ method is the most widely used. However, the $\mathrm{B} \& \mathrm{~B}$ method is not suitable to solve a nonlinear mixed integer programming (nMIP) problem, becasue the validity of the branching rules is tied with assumption of linearity. A method for nMIP problems is an approximate method based on conventional nonlinear programming technique. Since this method is based on the penalty function, all functions of objective and constraints have to be differentiable. Especially, when the problem is a multiobjective nMIP problem with fuzzy information, it is very difficult to solve. So we employ fuzzy goal programming technique in order to slove multiobjective nMIP problems with fuzziness.

The idea of goal programming was developed by Charnes and Cooper in the 1960's[1]. Since then, many researchers of various fields have devoted their efforts to this technique, such as Ijiri [2], Lee[3], Ignizio[4], Gen and Ida[5], and so on. The applications and practical adaptations of goal programming have been greatly developed until comparatively lately.

In the most real-world situations the expression of objectives by the decision maker is naturally imprecise or vague. So we need to use the fuzzy

遺伝的アルゴリズムによるファジィ多目標を持つシステム信 頼性最適化

玄 光男, 井田 憲一，金 鍾律

* Department of Industrial and Information Systems Engineering, Ashikaga Institute of Technology

足利工業大学:工学部経営情報工学科 theory and fuzzy programming method in order to represent imprecise circumstances. The fuzzy programming techniques can be useful during initial stages of the conceptual design of engineering systems where the design objectives have not been clearly indentified. Zimmermann[21] proposed fuzzy programming and linear programming. Narasimhan[18] considered the use of fuzzy set theory in goal programming for the first time. Tiwari, Dharamar, and Rao[19] [20] have investigated various aspects of decision problems using fuzzy goal programming. Sakawa[10] investigated the interactive method for fuzzy multiobjective optimization programming problems and the various multiobjective nonlinear programming techniques. Chu[17] investigated the fuzzy stochastic goal programming problems. And Dhingra[15] solved the fuzzy optimization problem whose objectives are nonlinear.

Recently, genetic algorithms have received a great deal of attention regarding their potential as optimization techniques for multicriteria optimization problems. Osyczka and Kundu[8] proposed a distance-based methods for multiple objective genetic algorithm. Tanino, Tanaka, and Hojo[9] proposed an interactive approach for the multiple objective genetic algorithm. Sakawa et al.[11] have formulated fuzzy multiobjective combinatorial optimization problems incorporating the fuzzy goals and introduced a genetic algorithm with double strings for deriving a compromise solutions by employing the fuzzy decision for combining the fuzzy goals. Sakawa and Kato[12] proposed genetic algorithms for fuzzy multiobjective 0-1 programming problems using fuzzy programming technique. Gen and Liu[13] investigated the applications of genetic algorithms to solve the nonlinear goal programming problem.

In this paper, we attempt to apply these genetic algorithms to the series-parallel system reliability optimization problem represented by the fuzzy non- 
linear mixed integer goal programming problems (f-nMIGP) which involve imprecise nonlinear mixed integer information. It is a pain in the neck to solve these problems because they have the mixed decision variables, i.e., real variables and integer ones. The main idea for solving the system reliability optimization problem formulated by fuzzy nonlinear mixed integer goal programming is to transform the original problem into the nonlinear mixed integer programming problem and solve the problem using the proposed genetic algorithm, without any transformation for this nonlinear problem into a linear model or other methods. We use the steepest descent method, which is a simple gradient method and called Cauchy's method, in order to have the proposed genetic algorithm increase the effectiveness. Finally, we try to get some numerical experiments which have multiobjectives and imprecise nonlinear mixed integer information, in order to demonstrate the effectiveness of the proposed method and compare the performance of our method with the one of GA proposed by Yokota, Gen, and $\mathrm{Li}[14]$.

\section{The f-nMIGP Formulation}

A typical formulation of f-nMIGP can be defined as follows:

Find $\boldsymbol{x}^{i}, \boldsymbol{x}^{r}$ to optimize three kind of fuzzy goals subject to $m$ nonlinear system constraints :

$$
\begin{aligned}
& f_{k}\left(\boldsymbol{x}^{i}, \boldsymbol{x}^{r}\right) \lesssim b_{k}, k=1,2, \cdots, q_{0} \\
& f_{k}\left(\boldsymbol{x}^{i}, \boldsymbol{x}^{r}\right) \gtrsim b_{k}, k=q_{0}+1, \cdots, q_{1} \\
& f_{k}\left(\boldsymbol{x}^{i}, \boldsymbol{x}^{r}\right) \equiv b_{k}, k=q_{1}+1, \cdots, q_{2}
\end{aligned}
$$

s.t.

$$
g_{c}\left(\boldsymbol{x}^{i}, \boldsymbol{x}^{r}\right) \leq G_{c}, c=1,2, \cdots, m
$$

where $\boldsymbol{x}^{i}$ is $n$-dimensional integer vector, $\boldsymbol{x}^{r}$ is $n$-dimensional real vector, the symbol $\lesssim$ (the type of fuzzy-min) referring to approximately less than or equal to the aspiration level $b_{k}$ signifies that the decision maker is satisfied even if greater than $b_{k}$ up to a certain tolerance limit, the symbol $\gtrsim$ (the type of fuzzy-max) referring to approximately greater than or equal to the aspiration level $b_{k}$ signifies that decision maker is satisfied even if less than $b_{k}$ up to a certain limit, the symbol $\equiv$ (the type of fuzzyequal) referring to that $f_{k}\left(\boldsymbol{x}^{i}, \boldsymbol{x}^{r}\right)$ should be in the vicinity of the aspiration $b_{k}$ signifies that the decision maker is satisfied even if greater than (or less than) $b_{k}$ up to a certain limit, $f_{k}\left(\boldsymbol{x}^{i}, \boldsymbol{x}^{r}\right)$ is the $k$-th nonlinear goal constraints, $g_{c}\left(\boldsymbol{x}^{i}, \boldsymbol{x}^{r}\right)$ is the $c$-th nonlinear system constraints, $b_{k}$ is the target value according to goal $k, G_{c}$ is the available resource of system constraint $c, q_{0}$ is the number of fuzzy-min goal constraints, $q_{1}-q_{0}$ is the number of fuzzy-max constraints, $q_{2}-q_{1}$ is the number of fuzzy-equal constraints, $m$ is the number of system constraints [17][20].

The membership functions[21] of the fuzzy goals can be defined as follows:

For fuzzy-equal,

$$
\begin{aligned}
& \mu_{k}\left(f_{k}\left(\boldsymbol{x}^{i}, \boldsymbol{x}^{r}\right)\right) \\
& =\left\{\begin{array}{l}
0 \quad \text { if } f_{k}\left(\boldsymbol{x}^{i}, \boldsymbol{x}^{r}\right)<b_{k}-t_{k}^{L}, \\
\frac{f_{k}\left(\boldsymbol{x}^{i}, \boldsymbol{x}^{r}\right)-\left(b_{k}-t_{k}^{L}\right)}{t_{k}^{L}} \\
\quad \text { if } b_{k}-t_{k}^{L} \leq f_{k}\left(\boldsymbol{x}^{i}, \boldsymbol{x}^{r}\right) \leq b_{k}, \\
1 \quad \text { if } f_{k}\left(\boldsymbol{x}^{i}, \boldsymbol{x}^{r}\right)=b_{k}, \\
1-\frac{f_{k}\left(\boldsymbol{x}^{i}, \boldsymbol{x}^{r}\right)-b_{k}}{t_{k}^{R}} \\
\quad \text { if } b_{k} \leq f_{k}\left(\boldsymbol{x}^{i}, \boldsymbol{x}^{r}\right) \leq b_{k}+t_{k}^{R}, \\
0 \quad \text { if } f_{k}\left(\boldsymbol{x}^{i}, \boldsymbol{x}^{r}\right)>b_{k}+t_{k}^{R}
\end{array}\right.
\end{aligned}
$$

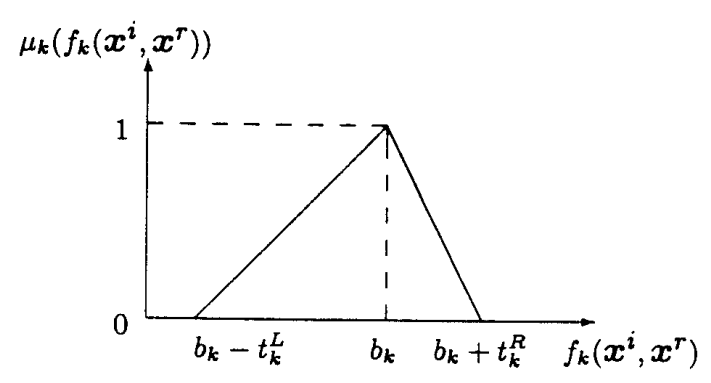

Figure 1 The membership function of fuzzy-equal

For fuzzy-min,

$$
\begin{aligned}
& \mu_{k}\left(f_{k}\left(\boldsymbol{x}^{i}, \boldsymbol{x}^{r}\right)\right) \\
& =\left\{\begin{array}{l}
1 \quad \text { if } f_{k}\left(\boldsymbol{x}^{i}, \boldsymbol{x}^{r}\right)<b_{k}, \\
1-\frac{f_{k}\left(\boldsymbol{x}^{i}, \boldsymbol{x}^{r}\right)-b_{k}}{t_{k}^{R}} \\
\quad \text { if } b_{k} \leq f_{k}\left(\boldsymbol{x}^{i}, \boldsymbol{x}^{r}\right) \leq b_{k}+t_{k}^{R}, \\
0 \quad \text { if } f_{k}\left(\boldsymbol{x}^{i}, \boldsymbol{x}^{r}\right)>b_{k}+t_{k}^{R}
\end{array}\right. \\
& \mu_{k}\left(f_{k}\left(\boldsymbol{x}^{i}, \boldsymbol{x}^{r}\right)\right)
\end{aligned}
$$

Figure 2 The membership function of fuzzy-min 
For fuzzy-max,

$$
\begin{aligned}
& \mu_{k}\left(f_{k}\left(\boldsymbol{x}^{i}, \boldsymbol{x}^{r}\right)\right) \\
& =\left\{\begin{array}{l}
0 \quad \text { if } f_{k}\left(\boldsymbol{x}^{i}, \boldsymbol{x}^{r}\right)<b_{k}-t_{k}^{L}, \\
\frac{f_{k}\left(\boldsymbol{x}^{i}, \boldsymbol{x}^{r}\right)-\left(b_{k}-t_{k}^{L}\right)}{t_{k}^{L}} \\
\quad \text { if } b_{k}-t_{k}^{L} \leq f_{k}\left(\boldsymbol{x}^{i}, \boldsymbol{x}^{r}\right) \leq b_{k}, \\
1 \quad \text { if } f_{k}\left(\boldsymbol{x}^{i}, \boldsymbol{x}^{r}\right)>b_{k}
\end{array}\right.
\end{aligned}
$$

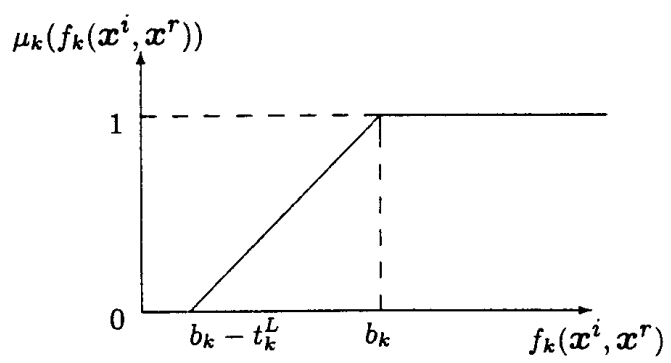

Figure 3 The membership function of fuzzy-max

In this paper we assume that membership functions are strictly monotone decreasing (or increasing) and continuous functions with respect to $f_{k}$ $\left(\boldsymbol{x}^{i}, \boldsymbol{x}^{r}\right)$, while $t_{k}^{L}$ is a maximal left tolerance limit to $b_{k}$ and $t_{k}^{R}$ is a maxmal right tolerance limit to $b_{k}$ (see Figure 1, Figure 1, and Figure 3 ).

Then formulation (1) is transformed into the following nonlinear mixed integer programming (nMIP) problem :

$$
\begin{array}{ll}
\max & \sum_{k=1}^{q_{2}} w_{k} \lambda_{k} \\
\text { s. t. } & \\
& \lambda_{k}=\mu_{k}\left(f_{k}\left(\boldsymbol{x}^{i}, \boldsymbol{x}^{r}\right)\right) \quad k=1,2, \cdots, q_{2} \\
& g_{c}\left(\boldsymbol{x}^{i}, \boldsymbol{x}^{r}\right) \leq G_{c} c=1,2, \cdots, m \\
& 0 \leq \lambda_{k} \leq 1 \quad k=1,2, \cdots, q_{2}
\end{array}
$$

where $w_{k}$ is the suitable weight factor which is assigned by the decision maker[20]. One of the major difficulties is that the decision maker sets the relative importance of goals correctly.

\section{A Genetic Algorithm}

Here we present a genetic algorithm used for solving series-parallel system reliability optimization problems represented by f-nMIGP problem.

\subsection{Representations and Initialization}

Let $\boldsymbol{V}$ denote the chromosomes in a population. For solving f-nMIGP problems, we can represent the chromosomes as follows:

$$
\boldsymbol{V}=\left[\left(x_{1}^{i}, x_{1}^{r}\right)\left(x_{2}^{i}, x_{2}^{r}\right) \cdots\left(x_{n}^{i}, x_{n}^{r}\right)\right]
$$

This representation of chromosome is convenient to manipulate $f$-nMIGP with $n$-dimensional mixed integer decision vector.

We firstly define pop_size as the number of chromosomes. pap_size chromosomes will be randomly initialized in its domain.

\subsection{Evaluation}

The evaluation function is defined in consideration of a weight factor as follows :

$$
\operatorname{eval}\left(\boldsymbol{V}_{p}\right)=\sum_{k=1}^{q_{2}} w_{k} \lambda_{k}, \quad p=1,2, \cdots, \text { pop_size }
$$

where $\lambda_{k}$ is given by (5), and $w_{k}$ is the weight factor considered the relative importance of goals (or objectives) and assigned by decision maker.

From the following equations, we can keep the best chromosome $V^{*}$ with the largest fitness value at each generation.

$$
V^{*}=\operatorname{argmax}\left\{\operatorname{eval}\left(\boldsymbol{V}_{p}\right) \mid p=1,2, \cdots, \text { pop_size }\right\}
$$

\subsection{Selection}

The selection used here is the method combined the roulette wheel and elitist approach. The roulette wheel selection, which is one of the fitnessproportional methods, is used to randomly reproduce into new generation, and the elitist method is employed to preserve the best chromosome for the next generation and overcome the stochastic errors of sampling. We employed the following selection procedure :

Step 1. Calculate a cumulative probability $a_{p}$ for each chromosome $V_{p},\left(p=1,2, \cdots, p o p \_s i z e\right)$. Step 2. Generate a random real number $r$ in $[0,1]$. Step 3. If $r \leq a_{1}$, then select the first chromosome $V_{1}$; otherwise select the $p$-th chromosome $V_{p}(2$ $\leq p \leq p o p_{-}$size) such that $a_{p-1}<r \leq a_{p}$.

Step 4. Repeat Steps 2 and 3 pop_size times and obtain pop_size copies of chromosomes.

Step 5 . If the best chromosome is not selected in the next generation, replace one randomly from new population by the best one.

Using this selection process, we can keep the best chromosome from the current generation to the next generation.

\subsection{Crossover}

In this paper, we employ arithmetical crossover in which it is defined as a convex combination of two chromosomes. When the constraint set is convex, the arithmetical crossover operation ensures that if both parents are feasible, both children are 
feasible. We define a parameter $p_{c}$ of a genetic process as the probability of crossover. This probability gives us the expected number $p_{c} \cdot p_{0} p_{-}$size of chromosomes which undergo the crossover operation.

We manipulate two kinds of variables, i.e., real variables and integer variables. For integer variables, we need to consider integer variables as real variables in order to carry out the arithmetical crossover operation. Then we truncate the decimals for integer variables after crossover operation and save only the integer part.

\subsection{Mutation}

Uniform mutation used in this paper. We define a parameter $p_{M}$ of a genetic process as the probability of mutation. This probability gives us the expected number $p_{M} \cdot p o p_{-}$size of chromosomes which undergo the mutation operation. Generating a random number $r$ in $[0,1]$, we select the given chromosome for mutation if $r<p_{M}$.

For a chosen parent $\boldsymbol{V}$, if the element $x_{j}$ of it is randomly selected for mutation, the resulted offspring is $\boldsymbol{V}^{\prime}=\left[\begin{array}{lllll}x_{1} & \cdots & x_{j}^{\prime} & \cdots & x_{n}\end{array}\right]$, where $x_{j}^{\prime}$ is a random(uniform probability distribution) value from $\left[x_{j}^{L}, x_{j}^{U}\right]$ if $x_{j}^{\prime}$ is integer variables then returns the integer random number. This operator ensures that the GA can search freely the search space from start to finish but has the shortcomings of divergence at later steps.

\subsection{Cauchy's method}

In this paper, we employ the Cauchy's method, also called by steepest descent method, as local optimization method, in order to improve GA proposed in this paper:

$$
\boldsymbol{V}^{\prime}=\boldsymbol{V}+\alpha \cdot \nabla f(\boldsymbol{V})
$$

where $\alpha$ is thet step length parameter and positive parameter, $\nabla f(\boldsymbol{V})$ is the gradient direction vector, $V$ means the chromosome after selection operation.

We can determine $\alpha$ such that $f\left(\boldsymbol{V}^{\prime}\right)$ is a optimum along $\nabla f(\boldsymbol{V})$, using an appropriate single-variable searching method and also can decide $\alpha$ when a differential function for $\alpha$ of $f\left(\boldsymbol{V}^{\prime}\right)$ is 0 . But these methods are difficult to decide $\alpha$ beçause the first method is hard to optimize the equation which has $\alpha$ as the variables and the second is also hard to calculate the Hessian matrix of objective function with many variables.

Therefore we approximate $\alpha$ as following method: For different cases we choose different directions $\nabla f(\boldsymbol{V})$; if $\boldsymbol{V}+\alpha \cdot \nabla f(\boldsymbol{V})$ is not fea- sible for the inequality constraints, then we set $\alpha$ as a random number between 0 and $\alpha$ until it is feasible. If the above process can not find a feasible solution in a predetermined number of iterations, we take $\alpha=0$. Thus the choromosome is $V^{\prime}=V+\alpha$. $\nabla f(\boldsymbol{V})$. For the maximizing objective function it may be better to choose the gradient direction; for the minimizing objective function it may be better to choose the negative of gradient direction.

Because the problem sloving in this paper has several objective functions, we calculate the gradient direction vector as the following equation: $\nabla f(\boldsymbol{V})=\sum_{i=1}^{n} w_{i} \cdot \nabla f_{i}(\boldsymbol{V})$ where $n$ is the number of objective functions.

In this paper, we employ the method mentioned above after selection operation in order to move the newly selected offsprings for the next generation to local optima before the next reproduction.

\subsection{Algorithm}

The algorithm for f-nMIGP problems is shown as follows:

\section{Step 0 : Set Parameters}

Set the population size( $p o p_{-}$size), mutation rate $\left(p_{M}\right)$, crossover rate $\left(p_{c}\right)$, maximum generation $(T)$, and initialize generation number $t=0$.

\section{Step 1 : Initialization}

Randomly produce initial population $\boldsymbol{V}_{p}(p=$ $1,2, \cdots$, pop_size) in its domain.

\section{Step 2 : Crossover}

Generate a random number $r$ in $[0,1]$. Select the given chromesome for crossover if $r<p_{c}$. Repeat this operation pop_size times.

For each pair of parents $\left(\boldsymbol{V}_{1}, \boldsymbol{V}_{2}\right)$, the crossover operation operator will produce the following two offsprings $\left(V^{\prime}{ }_{1}, V^{\prime}{ }_{2}\right)$ :

$$
\begin{aligned}
& \boldsymbol{V}_{1}^{\prime}=c_{1} \cdot \boldsymbol{V}_{1}+c_{2} \cdot \boldsymbol{V}_{2} \\
& \boldsymbol{V}^{\prime}{ }_{2}=c_{2} \cdot \boldsymbol{V}_{1}+c_{1} \cdot \boldsymbol{V}_{2}
\end{aligned}
$$

where $c_{1}+c_{2}=1$ and $c_{1}$ is a random number in $[0,1]$.

\section{Step 3 : Mutation}

Generate a random number $r$ in $[0,1]$. Select the chromosome $\boldsymbol{V}$

if $r<p_{M}$, repeat this operation $p o p_{-}$size times. Randomly select the element $x_{j}$ of a given parent $\boldsymbol{V}$. Mutate $x_{j}$ using uniform mutation method.

Step 4 : Calculate the fitness value 
Set $t=t+1$, and calculate $\operatorname{eval}\left(\boldsymbol{V}_{p}\right)(p=$ $1,2, \cdots$, pop_size) for each chromosome.

\section{Step 5 : Selection}

Select pop_size chromosomes for the next generation according to roulette wheel method and elitist selection method.

Step 6 : Cauchy's method Using the following eqaution, Move offsprings after selection to local optima before injecting into the next generation :

$$
\begin{aligned}
& \boldsymbol{V}_{p}^{\prime}=\boldsymbol{V}_{p}+\alpha \cdot \nabla f\left(\boldsymbol{V}_{p}\right) \\
& p=1,2, \cdots, p o p \_s i z e
\end{aligned}
$$

Step 7 : Terminating test

If $t<T$, return Step 2 for next generation.

If $t=T$, then terminate.

\section{Numerical Examples}

Here we used Pentium II PC and implemented by $\mathrm{C}$ language for solving the f-nMIGP problems using the proposed genetic algorithm. We will experiment three problems, in order to demonstrate the effectiveness of our proposed method and compare the performance of the proposed genetic algorithm and genetic algorithm proposed by Yokota et al. [14].

\subsection{Problem I}

The Problem I is a variation of optimal reliability allocation problem from reference[15] and one example of the nonlinear mixed integer programming problems. This problem inculdes not only the reliability maximization but also cost minimization and weight minimization. The f-nMIGP formulation for the Problem I can be formulated as follows:

Find $\boldsymbol{x}^{i}, \boldsymbol{x}^{r}$ to optimize the next fuzzy goals

$$
\begin{aligned}
& f_{1}\left(\boldsymbol{x}^{i}, \boldsymbol{x}^{r}\right)=\prod_{j=1}^{4}\left\{1-\left(1-x_{j}^{r}\right)^{x_{j}^{i}}\right\} \gtrsim b_{1} \\
& f_{2}\left(\boldsymbol{x}^{i}, \boldsymbol{x}^{r}\right)=\sum_{j=1}^{4} C\left(x_{j}^{r}\right) \cdot\left(x_{j}^{i}+\exp \left(\frac{x_{j}^{i}}{4}\right)\right) \lesssim b_{2}
\end{aligned}
$$

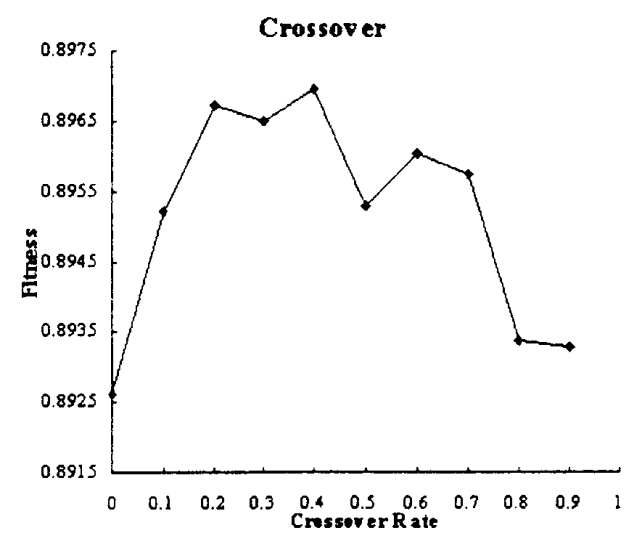

(a) Crossover

$$
\begin{aligned}
& f_{3}\left(\boldsymbol{x}^{i}\right)=\sum_{j=1}^{4} d_{j} \cdot x_{j}^{i} \cdot \exp \left(\frac{x_{j}^{i}}{4}\right) \lesssim b_{3} \\
& \text { s.t. } \\
& \qquad g_{1}\left(\boldsymbol{x}^{i}\right)=\sum_{j=1}^{4} v_{j} \cdot\left(x_{j}^{i}\right)^{2} \leq 250 \\
& \quad 1 \leq x_{j}^{i} \leq 10, \text { positive } \text { integer } j=1, \cdots, 4 \\
& 0.5 \leq x_{j}^{r} \leq 1-10^{-6} \text {, real number } j=1, \cdots, 4
\end{aligned}
$$

where $x_{j}^{i}$ is the number of redundant components at subsystem $j, x_{j}^{r}$ is the reliability of component at subsystem $j, v_{j}$ is the product of weight \& volume per element at subsystem $j, d_{j}$ is the weight of each components at the subsystem $j, F_{1}$ is equal to $b_{1}-$ $t_{1}^{L}, F_{2}$ is equal to $b_{2}+t_{2}^{R}, F_{3}$ is equal to $b_{3}+t_{3}^{R}$, and $C\left(x_{j}^{r}\right)$ is the cost of each component with reliability $x_{j}^{r}$ at subsystem $j$ as follows:

$$
C\left(x_{j}^{r}\right)=\alpha_{j} \cdot\left(\frac{-t_{0}}{\ln \left(x_{j}^{r}\right)}\right)^{\beta_{j}}, j=1, \cdots, 4
$$

\begin{tabular}{|c|c|c|c|c|}
\hline \multicolumn{2}{|c|}{ Number of subsystems } & \multicolumn{3}{|c|}{4} \\
\hline \multicolumn{2}{|c|}{ Limit on $F_{1}$} & \multicolumn{3}{|c|}{0.75} \\
\hline \multicolumn{2}{|l|}{ Limit on $F_{2}$} & \multicolumn{3}{|c|}{400.0} \\
\hline \multicolumn{2}{|l|}{ Limit on $F_{3}$} & \multicolumn{3}{|c|}{500.0} \\
\hline \multicolumn{2}{|c|}{ Operating time $t_{O}$} & \multicolumn{3}{|c|}{1000 hours } \\
\hline subsystem & $10^{5} \cdot \alpha_{j}$ & $\beta_{j}$ & $v_{j}$ & $d_{j}$ \\
\hline 1 & 1.0 & 1.5 & 1 & 6 \\
\hline 2 & 2.3 & 1.5 & 2 & 6 \\
\hline 3 & 0.3 & 1.5 & 3 & 8 \\
\hline 4 & 2.3 & 1.5 & 2 & 7 \\
\hline
\end{tabular}

where $\alpha_{j}, \beta_{j}$ are constants representing the physical characteristic of each component at subsystem $j$, and $t_{o}$ is the operating time duringwhich the component must not fail.

The design data for this problem is in the Table 1. After parameter tuning, as shown in Figure 4 and Figure 5 by experimenting the GA proposed in

Table 1 The design data of Problem I

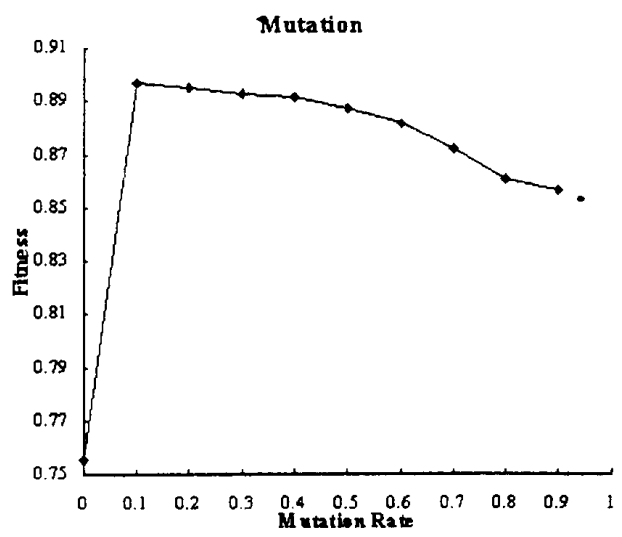

(b) Mutation 
this paper several times, we get the parameters as pop_size $=20, p_{c}=0.4, p_{M}=0.1$, and $T=2000$. Also we set the parameters as $t_{1}^{L}=0.25, t_{2}^{R}=300, t_{3}^{R}$ $=360$ and selected the relative weights of objectives $(0.5,0.25,0.25)$, in order to give first objective twice as important as other objectives. Our experiments are performed with the parameters mentioned above for Problem 1.

For the performance comparision between the proposed GA and GA suggested by Yokota et al., we had several experiments and the result is shown in Figure 6 and Table 2.

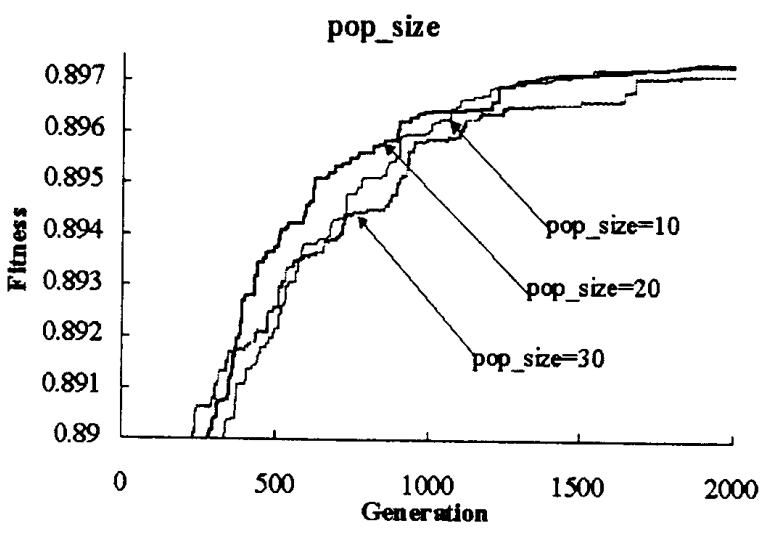

Figure 5 The pop_size for Genetic operator

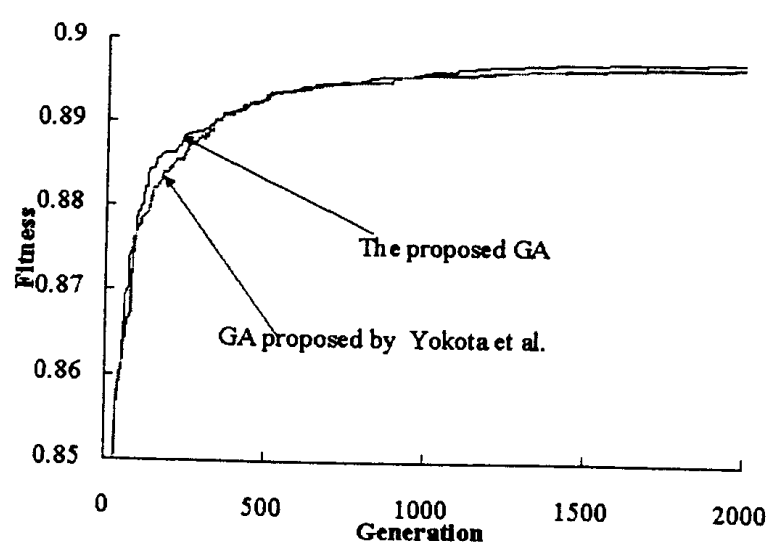

Figure 6 The Genetic Processes for Problem I

Table 2 The Performance Comparision for Problem I

\begin{tabular}{|c|c|c|c|}
\hline & & $\mathrm{GA}$ & Proposed GA \\
\hline $\begin{array}{r}\mathrm{Av} \\
\mathrm{CPU} \\
(\mathrm{s}\end{array}$ & $\begin{array}{l}\text { rage } \\
\text { Time } \\
\text { c.) }\end{array}$ & 4.427 & 18.7125 \\
\hline & Average & 0.896845 & 0.897456 \\
\hline Fitness & Worst & 0.894179 & 0.896436 \\
\hline & Best & 0.897654 & 0.897773 \\
\hline & STD & 0.000894 & 0.000339 \\
\hline
\end{tabular}

STD: Standard Deviation, GA: Yokota et al.'s GA
From Figure 6 and Table 2, we can see that the proposed GA outperforms Yokota et al.'s approach. Figure 6 illustrates that the proposed GA is better than Yokota et al.'s approach in convergence to the best compromise solution. But as shown in Table 2, the proposed GA take the longer average computing time than Yokota et al.'s approach.

The best solution for Problem I of the proposed GA is found in 1923-th generation with objectives $f_{1}$ $\left(\boldsymbol{x}^{i}, \quad \boldsymbol{x}^{r}\right)=0.982335, f_{2}\left(\boldsymbol{x}^{i}, \quad \boldsymbol{x}^{r}\right)=135.001259, f_{3}$ $\left(\boldsymbol{x}^{i}\right)=147.048541$, and solution $[(3,0.853070)$, $(3,0.821421),(2,0.939903),(3,0.825620)]$. The optimal solution of Problem $I$ in reference [15] are $f_{1}\left(\boldsymbol{x}^{i}, \boldsymbol{x}^{r}\right)=0.94478, f_{2}\left(\boldsymbol{x}^{i}, \boldsymbol{x}^{r}\right)=104.472, f_{3}\left(\boldsymbol{x}^{i}\right)=$ 128.727 with $[(2,0.86504),(3,0.81814),(2$, $0.84253),(3,0.80645)]$. The result of our method is satisfactory and acceptable.

\subsection{Problem II}

Problem II is a variation of the system reliability optimization problem with 5-subsystem series-parallel system [16] and another example of the nonlinear mixed integer programming problem.

Now we consider a f-nMIGP formulation for Problem II shown as follows :

Find $\boldsymbol{x}^{i}, \boldsymbol{x}^{r}$ to optimize the next fuzzy goals

$$
\begin{aligned}
& f_{1}\left(\boldsymbol{x}^{i}, \boldsymbol{x}^{r}\right)=\prod_{j=1}^{5}\left\{1-\left(1-x_{j}^{r}\right)^{x_{j}^{i}}\right\} \gtrsim b_{1} \\
& f_{2}\left(\boldsymbol{x}^{i}\right)=\sum_{j=1}^{5} d_{j} \cdot x_{j}^{i} \cdot \exp \left(\frac{\mathrm{x}_{j}^{i}}{4}\right) \leqq \mathrm{b}_{2} \\
& \text { s. t. } \\
& \qquad g_{1}\left(\boldsymbol{x}^{i}\right)=\sum_{j=1}^{5} v_{j} \cdot\left(x_{j}^{i}\right)^{2} \leq G_{1} \\
& \quad g_{2}\left(\boldsymbol{x}^{i}, \boldsymbol{x}^{r}\right)=\sum_{j=1}^{5} C\left(x_{j}^{r}\right) \cdot\left(x_{j}^{i}+\exp \left(\frac{x_{j}^{i}}{4}\right)\right) \leq G_{2} \\
& \quad x_{j}^{i} \geq 1, \text { positive integer } \quad j=1, \cdots, 5 \\
& 0 \leq x_{j}^{r} \leq 1 \text {, real number } j=1, \cdots, 5
\end{aligned}
$$

where $C\left(x_{j}^{r}\right)$ can be represented by the following equation :

$$
C\left(x_{j}^{r}\right)=\alpha_{j} \cdot\left(\frac{-t_{0}}{\ln \left(x_{j}^{r}\right)}\right)^{\beta_{j}}, j=1, \cdots, 5
$$

The design data for this f-nMIGP problem is shown in Table 3 . We have the parameters' settings for Problem II as follows : pop_size $=20$, $T=2000, p_{c}=0.4, p_{M}=0.1, t_{1}^{L}=0.25, t_{2}^{R}=120$. And we set the relative weights of fuzzy goals $(0.75,0.25)$. 
Table 3 The design data of Problem II

\begin{tabular}{|c|c|c|c|c|}
\hline \multicolumn{2}{|c|}{ Number of subsystems } & \multicolumn{3}{|c|}{5} \\
\hline \multicolumn{2}{|c|}{ Limit on $F_{1}$} & \multicolumn{3}{|c|}{0.75} \\
\hline \multicolumn{2}{|l|}{ Limit on $F_{2}$} & \multicolumn{3}{|c|}{400.0} \\
\hline \multicolumn{2}{|l|}{ Limit on $G_{1}$} & \multicolumn{3}{|c|}{220.0} \\
\hline \multicolumn{2}{|c|}{ Limit on $G_{2}$} & \multicolumn{3}{|c|}{350.0} \\
\hline \multicolumn{2}{|c|}{ Operating time $t_{O}$} & \multicolumn{3}{|c|}{1000 hours } \\
\hline subsystem & $10^{5} \cdot \alpha_{j}$ & $\beta_{j}$ & $v_{j}$ & $d_{j}$ \\
\hline 1 & 2.33 & 1.5 & 1 & 7 \\
\hline 2 & 1.45 & 1.5 & 2 & 8 \\
\hline 3 & 0.541 & 1.5 & 3 & 8 \\
\hline 4 & 8.05 & 1.5 & 4 & 6 \\
\hline 5 & 1.95 & 1.5 & 2 & 9 \\
\hline
\end{tabular}

Table 4 The Performance Comparision for Problem II

\begin{tabular}{|c|c|c|c|}
\hline \multicolumn{2}{|c|}{$\begin{array}{c}\text { Average } \\
\text { CPU Time } \\
\text { (sec.) }\end{array}$} & 5.907 & 19.661 \\
\hline \multirow{4}{*}{ Fitness } & Average & 0.957442 & 0.963852 \\
\cline { 2 - 4 } & Worst & 0.946778 & 0.956742 \\
\cline { 2 - 4 } & Best & 0.965478 & 0.968382 \\
\cline { 2 - 4 } & STD & 0.005282 & 0.003348 \\
\hline
\end{tabular}

STD: Standard Deviation, GA: Yokota et al.'s GA

\subsection{Problem III}

Here we consider a similar five-subsytem problem as in the Problem II is solved, but where the design data is Table $5[16]$. We use the following mathematical model for Problem III with the design data of Table 5 :

Find $\boldsymbol{x}^{i}, \boldsymbol{x}^{r}$ to optimize the next fuzzy goals

$$
\begin{aligned}
& f_{1}\left(\boldsymbol{x}^{i}, \boldsymbol{x}^{r}\right)=\prod_{j=1}^{5}\left\{1-\left(1-x_{j}^{r}\right)^{x_{j}^{i}}\right\} \gtrsim b_{1} \\
& f_{2}\left(\boldsymbol{x}^{i}, \boldsymbol{x}^{r}\right)=\sum_{j=1}^{5} C\left(x_{j}^{r}\right) \cdot\left(x_{j}^{i}+\exp \left(\frac{x_{j}^{i}}{4}\right)\right) \lesssim b_{2} \\
& f_{3}\left(\boldsymbol{x}^{i}\right)=\sum_{j=1}^{5} d_{j} \cdot x_{j}^{i} \cdot \exp \left(\frac{x_{j}^{i}}{4}\right) \lesssim b_{3}
\end{aligned}
$$

s. t.

$$
\begin{aligned}
& g_{1}\left(\boldsymbol{x}^{i}\right)=\sum_{j=1}^{5} v_{j} \cdot\left(x_{j}^{i}\right)^{2} \leq G_{1} \\
& x_{j}^{i} \geq 1, \text { positive integer } j=1, \cdots, 5 \\
& 0 \leq x_{j}^{r} \leq 1, \text { real number } j=1, \cdots, 5
\end{aligned}
$$

where $C\left(x_{j}^{r}\right)$ can be represented by the following

\begin{tabular}{|c|c|c|c|c|}
\hline \multicolumn{2}{|c|}{ Number of subsystems } & \multicolumn{3}{|c|}{5} \\
\hline \multicolumn{2}{|c|}{ Limit on $F_{1}$} & \multicolumn{3}{|c|}{0.75} \\
\hline \multicolumn{2}{|l|}{ Limit on $F_{2}$} & \multicolumn{3}{|c|}{205.0} \\
\hline \multicolumn{2}{|l|}{ Limit on $F_{3}$} & \multicolumn{3}{|c|}{240.0} \\
\hline \multicolumn{2}{|l|}{ Limit on $G_{1}$} & \multicolumn{3}{|c|}{110.0} \\
\hline \multicolumn{2}{|c|}{ Operating time $t_{O}$} & \multicolumn{3}{|c|}{1000 hours } \\
\hline subsystem & $10^{5} \cdot \alpha_{j}$ & $\beta_{j}$ & $v_{j}$ & $d_{j}$ \\
\hline 1 & 2.33 & 1.5 & 1 & 7 \\
\hline 2 & 1.45 & 1.5 & 2 & 8 \\
\hline 3 & 0.541 & 1.5 & 3 & 8 \\
\hline 4 & 8.05 & 1.5 & 4 & 6 \\
\hline 5 & 1.95 & 1.5 & 2 & 9 \\
\hline
\end{tabular}
equation:

$$
C\left(x_{j}^{r}\right)=\alpha_{j} \cdot\left(\frac{-t_{0}}{\ln \left(x_{j}^{r}\right)}\right)^{\beta_{j}}, \quad j=1, \cdots, 5
$$

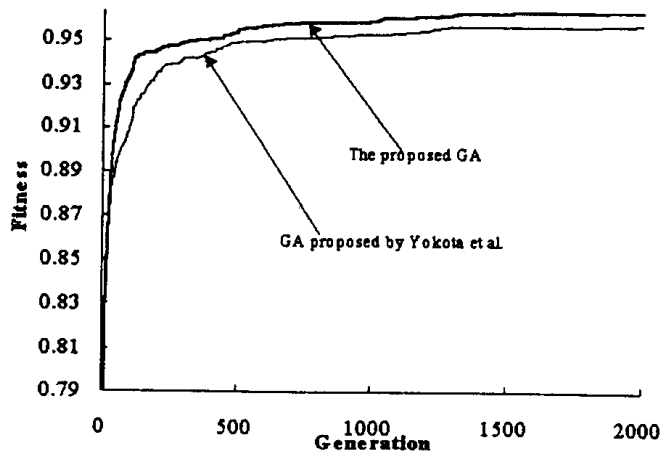

Figure 7 The Genetic Processes for Problem II

Table 5 The design data of Problem III

Table 6 The Performance Comparision for Problem III

\begin{tabular}{|c|c|c|c|}
\hline \multicolumn{2}{|c|}{} & GA & Proposed GA \\
\hline $\begin{array}{c}\text { Average } \\
\text { CPU Time } \\
\text { (sec.) }\end{array}$ & 5.3005 & 23.6125 \\
\hline \multirow{3}{*}{ Fitness } & Average & 0.699208 & 0.710613 \\
\cline { 2 - 4 } & Worst & 0.654877 & 0.676798 \\
\cline { 2 - 4 } & Best & 0.727734 & 0.730113 \\
\cline { 2 - 4 } & STD & 0.022590 & 0.013156 \\
\hline
\end{tabular}

STD: Standard Deviation, GA: Yokota et al.'s GA

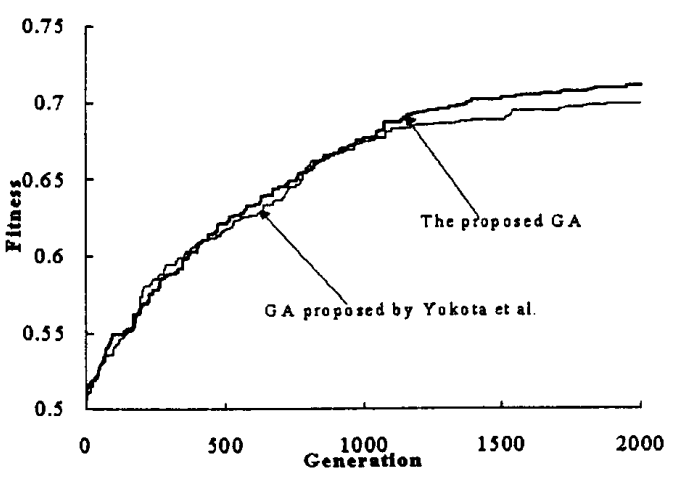

Figure 8 The Genetic Processes for Problem III 
We set the parameters for Problem III as fol lows: $p o p \_s i z e=20, T=2000, p_{c}=0.4, p_{M}=0.1$, $t_{1}^{L}=0.25, t_{2}^{R}=40, t_{33}^{R}=50$. And we supposed the relative weights of fuzzy goals $(0.5,0.25,0.25)$.

The result of Problem III is shown in Table 6 and Figure 8. From Table 6 and Figure 8, we can also see that the proposed GA outperforms approach proposed by Yokota et al.

The best result for Problem III of the proposed GA is found in 1914-th generation with objectives $f_{1}$ $\left(\boldsymbol{x}^{i}, \boldsymbol{x}^{r}\right)=0.924627, f_{2}\left(\boldsymbol{x}^{i}, \boldsymbol{x}^{r}\right)=165.229873, f_{3}$ $\left(\boldsymbol{x}^{i}\right)=192.481082$, and solution $[(3,0.780943)$, $(2,0.852900),(2,0.901031),(3,0.700890),(3$, $0.792657)]$.

\section{Conclusion}

Due to the feature of their different kinds of variable, MIP problems are difficult to manipulate. Especially, MIP problems with multiple objectives and fuzzy nonlinear informations are more difficult to treat. So we transformed the original problem into the modified problem using fuzzy goal programming technique which is one of the powerful methods for multiobjective problems with fuzziness, in order to solve MIP problem with multiple objectives and fuzzy nonlinear informations.

One of the advantages of genetic algorithm is to obtain the global or near-global optima fairly well for the complex problems with nonlinear objective functions. And genetic algorithm can solve the problems which have the nonlinearity, without changing the problems.

In this paper, we presented the genetic algorith$m$ for reliability optimization problem of mixed multistage series-parallel system, which is formulated by f-nMIGP. The proposed genetic algorithm was applied in three numerical examples in order to demonstrate the effectiveness of our method. All the results of our examples are satisfactory and aceeptable. From the results, we can see that the proposed GA has a better efficiency than Yokota et al.'s approach.

The next research may include high qualified genetic operators which maintain the diversity of the population in order to find the solution with higher accuracy for f-nMIGP problems and hybridize the genetic algorithm with various methods of hybridization, such as domain-specific techniques for real-world optimization, neighborhood search method, and so on.

\section{Acknowledgment}

This research was supported by the International Scientific Research Program, the Grant-inAid for Scientific Research(No. 07045032 : 1995.41998.3) by the Ministry of Education, Science and Culture, the Japanese Government.

\section{References}

[ 1 ] Charnes A. and W. W. Cooper, Management Models and Industrial Applications of Linear Programming, John Wiley \& Sons, New York, 1961.

[2]Ijiri Y.,Management Goals and Accounting for Control, Rand-McNally, Chicago, 1965.

[3]Lee S., Goal Programming for Decision Analysis, Auerbach, 1972.

[4]Ignizio J., Linear Programming in Single \& Multiple-Objective System, Prentice-Hall, 1981.

[5] Gen M. and K. Ida, Goal Programming Using Turbo C, HBJ Pub., Tokyo, 1993 (in Japanese).

[6] Michalewicz Z., Genetic Algorithms + Data Structures $=$ Evolution Programs, 2nd ed., SpringerVerlag, New York, 1994.

[7]Gen, M. \& Cheng, R., Genetic Algorithms and Engineering Design, John Wiley \& Sons, New York, 1997.

[ 8 ] Osyczka, A. and S. Kundu, A new method to solve generalized multicriteria optimization problems using genetic algorithm, Structural Optimization, Vol.10, No.2, pp.94-99, 1995.

[ 9 ] Tanino T., M. Tanaka, and C. Hojo, An interactive multicriteria decision making method by using a genetic algorithm, In Proc. of International Conference on System Science \& System Engineering, pp. 381-386, 1993.

[10]Sakawa, M., Fuzzy Sets and Interactive Multiobjective Optimization, Plenum Press, New York, 1993.

[11]Sakawa, M., M. Inuiguchi, H. Sunada and K. Sawada, Fuzzy multiobjective combinatorial optimization through revised genetic algorithms. Journal of Japan Society for Fuzzy Theory and Systems, Vol. 6, pp.177-186, 1994 (in Japanese).

[12] Sakawa, M., K. Kato, Genetic algorithms with decomposition procedures for fuzzy multiobjective 0-1 programming problems with block angular structure, Proceeding of IEEE International Conference on Evolutionary Computation, pp.706-709(1996).

[13] Gen, M. and B. Liu, A genetic algorithm for nonlinear goal programming, Research Report, Vol.23, pp.141-148, Ashikaga Institute of Technology, Ashikaga, 1996.

[14] Yokota, T., M. Gen, and Y. Li, Genetic Algorithm for non-linear mixed integer programming problems and its applications, Computers and Industrial Engineering, Vol. 30, No. 4, pp. 905-917, 1996.

[15] Dhingra, A. K., Optimal apportionment of reliability and redundancy in series system under mutiple objectives, IEEE Trans. on Reliability, Vol.41, No. 
4, pp.576-582, 1992.

[16] Jacobson, D. W. and S. R. Arora, Simultaneous allocation of reliability \& redundancy using simplex search, Proceedings of Annual Reliability and Maintainability Symposium, pp.243-250, 1996.

[17]Chu, T. C. , Some Problems in Fuzzy Decision Making, Ph. D. Dissertation, U. of Texas at Arlington, 1993.

[18] Narasimhan, R. , Goal programming in a fuzzy environment, Decision Sciences, Vol.11, pp.325-336, 1980.

[19] Tiwari, R. N., S. Dharmar, and J. R. Rao,Priority structure in fuzzy goal programming, Fuzzy Sets and Systems, Vol.19, pp.251-259, 1986.

[20] Tiwari, R. N., S. Dharmar, and J. R. Rao, Fuzzy goal programming-an additive model, Fuzzy Sets and Systems, Vol.24, pp.27-34, 1987.
[21]Zimmerman, H.-J., Fuzzy programming and linear programming with several objective functions, Fuzzy Sets and Systems Vol.1, pp.45-55, 1978.

(1997年 8 月 7 日 受 付)

(1997年12月11日 再受付)

[問い合わせ先]

Mitsuo GEN

Department of Industrial and Information Systems

Engineering, Graduate School of Engineering,

Ashikaga Institute of Technology

268-1 Ohmae-cho, Ashikaga, 326-8558 Japan

TEL : 0284-62-0605 (ext.376)

FAX : 0284-64-1071

E-mail : gen@genlab.ashitech.ac.jp

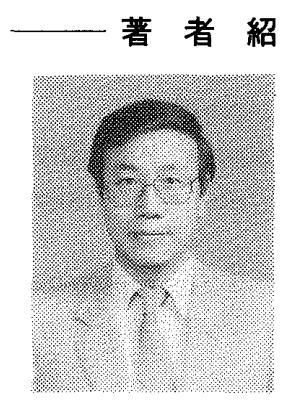

\section{Mitsuo GEN}

Department of Industrial and Information Systems Engineering, Graduate School of Engineering, Ashikaga Institute of Technology

He is a professor in the Department of Industrial and Information Systems Engineering at Ashikaga Institute of Technology, Japan. He received his M. S. and Ph.D. from Kogakuin University, Japan. His research interest includes reliability analysis, fuzzy operations research, network optimization, neural networks, and genetic algorithms. He has published several books including the book Genetic Algorithms and Engineering Design with Dr. R.Cheng by John Wiley \& Sons, Inc. He has published decades of articles in several international journals such as IEEE Transcations on Reliability, European Journal of Operational Research, Computers \& Operations Research, Computers \& Industrial Engineering, International Journal of Systems Science, Fuzzy Sets \& Systems, Networks, and Engineering Design \& Automation. He is also a member of the editorial board of the International Journal of Computers \& Industrial Engineering and associate editor of Engineering Design \& Automation.

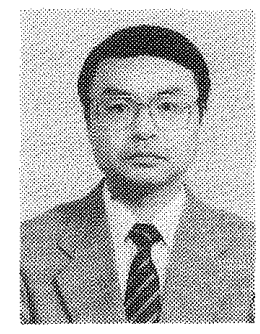

\section{Kenichi IDA}

Department of Industrial and Information Systems Engineering, Graduate School of Engineering, Ashikaga Institute of Technology

$\mathrm{He}$ is a professor in the Department of Industrial and Information Systems Engineering at Ashikaga Institute of Technology, Japan. He received his M. S. and Ph.D. from Kogakuin University, Japan. His research interests include methods of system optimization and numerical analysis and development of fuzzy mathematical programming software. He co-authored Numerical Analysis Library for Personal Computers (HBJ Publishers, 1986) among others. He is a member of Japan Operations Research Society, Japan Industrial Management Association, Information Processing Society of Japan, Japan Society for Fuzzy Theory \& Systems, and IIE.

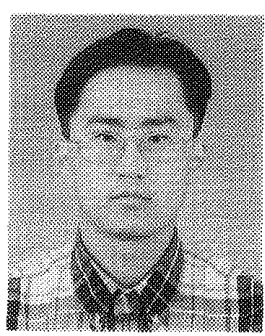

\section{Jongryul KIM}

Department of Industrial and Information Systems Engineering, Graduate School of Engineering, Ashikaga Institute of Technology

$\mathrm{He}$ is a $\mathrm{Ph} . \mathrm{D}$. candidate student in the Department of Industrial and Systems Engineering at Ashikaga Institute of Technology, Japan. $\mathrm{He}$ received his M.S. from Ashikaga Institue of Technology, Japan. His research interests network optimization, system reliability, and network reliability, and genetic algorithm. He is a member of Japan Society for Fuzzy Theory \& Systems. 


\section{System Reliability Optimization with Fuzzy Goals Using Genetic Algorithm}

by

\section{Mitsuo GEN, Kenichi IDA, Jongryul KIM}

\section{Abstract :}

Goal programming is one of the powerful methods for multiobjective decision making and is one of the excellent models for multiobjective decision making problem in many real-world problems. But in real-world problems such as the optimal design problems of system reliability, these problems are formulated by mixed integer programming model with nonlinear objective functions, real variables, and integer variables. There are many cases that the goal establishment of these objectives is difficult and imprecise.

In this paper, we attempt to apply genetic algorithms, which have received a great deal of attention about their ability as optimization techniques for combinatorial problems and have been used to solve multiobjective decision making problems, to the reliability optimization problem formulated by fuzzy nonlinear mixed integer programming problem. Nonlinear mixed integer programming problem having fuzziness is difficult to solve directly. Fuzzy nonlinear mixed integer programming problem with multiple objectives is harder to manipulate. Therefore we employ the fuzzy goal programming technique to transform the system reliability optimization problem depicted by the fuzzy nonlinear mixed integer programming problem into the nonlinear mixed integer programming problem. We use the genetic algorithm to slove the nonlinear mixed integer programming problem without any transformation for nonlinear problem into a linear model or other methods. Also, we introduce the steepest descent method in order to make the proposed genetic algorithm better.

Finally, we try to get some numerical experiments which have multiobjective, and imprecise nonlinear mixed integer information, using fuzzy goal programming and genetic algorithm.

Keywords : Fuzzy Goal Programming, Nonlinear Mixed Integer Programming, Genetic Algorithm(GA)

\section{Contact Address : Mitsuo GEN}

Department of Industrial and Information Systems Engineering, Graduate School of Engineering, Ashikaga Institute of Technology

268-1 Ohmae-cho, Ashikaga, 326-8558 Japan

TEL : 0284-62-0605(ext.376)

FAX : 0284-64-1071

E-mail : gen@genlab.ashitech.ac.jp

\section{遺伝的アルゴリズムによる ファジィ多目標を持つシステム信頼性最適化}

目標計画法は塞社会における現実の意思決定問題に对するもつとも有効な多目的意思決定手法の一つである。 しかし、現実の意思決定問題、例えばシステム信頼性の最適設計問題では実数と整数の変数を伴う非線形な混 合整数計画モデルとして定式化され、なおかつ目標の設定が難しく、また暧味な場合が多い。

本論文では、最近組合せ問題の有効な解法の一つとして注目され、多目的最適化問題に多く適用されている 遗伝的アルゴリズムを改良し、あいまいな目標、すなわちファジィ目標を伴う非線形混合整数目標計画問題と して定式化された信頼性最適化問題の解法として適用することを試みる。一般に、ファジィ性を持つ非線形混 合整数計画問題は解くことが難しく、特に多目的を伴うファジィ非線形混合整数計画問題を直接的に解くこと は困難である。そこで、本研究では、まずファジィ目標計画法を利用してファジィ非線形混合整数計画問題に 定式化された信頼性最適化問題を通常の非線形混合整数計画問題に变換し、その非線形混合整数計画問題を遺 伝的アルゴリズムを用いて線形化することなく、直接解く手法を提案する。また、ここで提案する遺伝的アル ゴリズムは求解効率を上げるために最急降下法を導入している。さらに、数值実験により提案する手法の有効 性を確認する。

キーワード：ファジィ目標計画、非線形混合整数計画、遺伝的アルゴリズム 